Original Article

\title{
ANALYSIS OF DOXORUBICIN AND DOXORUBICINOL IN DRIED BLOOD SPOT OF BREAST CANCER PATIENTS FOR MONITORING THE CARDIOTOXICITY OF DOXORUBICIN
}

\author{
YAHDIANA HARAHAP' ${ }^{1}$, SABRINA NUR AMALIA ${ }^{1}$, ALDHI ANARTA1, RAMADHAN² \\ ${ }^{1}$ Faculty of Pharmacy, Universitas Indonesia, Depok 16424, West Java, Indonesia, ${ }^{2}$ Dharmais Cancer Hospital, Jakarta, 11420, Indonesia \\ Email: yahdiana03@yahoo.com
}

Received: 26 Dec 2019, Revised and Accepted: 27 Feb 2020

\section{ABSTRACT}

Objective: This study aimed to analyze doxorubicin and doxorubicinol levels in Dried Blood Spot (DBS) from 25 breast cancer patients who received doxorubicin in their therapeutic regiment.

Methods: DBS samples were extracted by protein precipitation method and analyzed using Ultra Performance Liquid Chromatography tandem Mass Spectrometry (LC-MS/MS), with the Acquity UPLC BEH C18 Waters chromatography column $(2.1 \times 100 \mathrm{~mm} \times 1.7 \mu \mathrm{m})$. The mobile phase consisted of $0.1 \%$ acetic acid (eluent A) and acetonitrile (eluent B) with gradient elution; the flow rate was $0.15 \mathrm{ml} / \mathrm{min}$ and runtime, $7 \mathrm{~min}$. This method was linear within the concentration range of $10-200 \mathrm{ng} / \mathrm{ml}$ for doxorubicin and $4-100 \mathrm{ng} / \mathrm{ml}$ for doxorubicinol.

Result: The analysis results showed that doxorubicin levels were in the range of $11.01 \mathrm{ng} / \mathrm{ml}$ to $93.75 \mathrm{ng} / \mathrm{ml}$ and doxorubicinol was $5.80 \mathrm{ng} / \mathrm{ml}$ to $58.57 \mathrm{ng} / \mathrm{ml}$.

Conclusion: Cumulative doses of all patients were in the range of $49.11 \mathrm{mg} / \mathrm{m}^{2}$ to $303.70 \mathrm{mg} / \mathrm{m}^{2}$, which have cardiomyopathy incidence rates $<4 \%$.

Keywords: Doxorubicin, Doxorubicinol, Dried blood spot, Breast cancer, LC-MS/MS

(C) 2020 The Authors. Published by Innovare Academic Sciences Pvt Ltd. This is an open access article under the CC BY license (http://creativecommons.org/licenses/by/4.0/) DOI: http://dx.doi.org/10.22159/ijpps.2020v12i4.36707. Journal homepage: https://innovareacademics.in/journals/index.php/ijpps

\section{INTRODUCTION}

Doxorubicin is one of the anti-cancer drugs effectively used in the treatment of breast cancer as adjuvant chemotherapy. Doxorubicin is an anthracycline drug used as an anticancer drug with a mechanism to form complexes with DNA and inhibit DNAdependent synthesis of mRNA. In the body, doxorubicin is metabolized into more active metabolites, namely doxorubicinol as the main metabolite and other metabolites, namely adriamyclic aglycones. Doxorubicinol has long-term side effects, namely cardiotoxic with accumulating concentrations. Doxorubicinol can disrupt the $\mathrm{Ca}^{2+i o n}$ pump, which results in disrupted $\mathrm{Ca}^{2+}$ homeostasis. The use of doxorubicin in the long term causes the accumulation of doxorubicinol in the body, which can increase the risk of heart problems. Current evidence indicates that the incidence of cardiomyopathy at a rate of $4 \%$ at doses of $500-550 \mathrm{mg} / \mathrm{m}^{2}, 18 \%$ at doses of $551-600 \mathrm{mg} / \mathrm{m}^{2}$ and $36 \%$ at doses $>600 \mathrm{mg} / \mathrm{m}^{2}$ (all cumulative doses) $[1,2]$.

Doxorubicin is metabolized by carbonyl-1-reductase (CBR1) and carbonyl-3-reductase (CBR3) enzymes to doxorubicinol. Genetic polymorphism in CBR3 associated with differences in cardiac outcomes in pediatric patients consuming doxorubicin and polymorphism in CBR1 correlated with high levels of doxorubicin so that the levels of intracellular doxorubicinol are low $[3,4]$. Based on this, Therapeutic Drug Monitoring (TDM) is needed for breast cancer patients who received doxorubicin in their treatment regimens. Doxorubicin TDM can be carried out by simultaneous analysis of doxorubicin and doxorubicinol in blood.

In this study, analysis of doxorubicin and doxorubicinol in Dried Blood Spot (DBS) of breast cancer patients was carried out. DBS are innovative bio sampling techniques in which blood samples are imprinted on absorbent paper or other material paper [5]. The volume of blood samples needed using this technique tends to be less than the venipuncture technique, which requires more sample volume. Therefore, sampling using this technique further increases patient comfort. DBS samples from 25 breast cancer patients were extracted by protein precipitation method and analyzed using Liquid Chromatography tandem Mass
Spectrometry (LC-MS/MS). The results of the analysis will be seen quantitatively as a form of Therapeutic Drug Monitoring (TDM) in breast cancer patients, who received the document in this therapeutic regimen for the future.

\section{MATERIALS AND METHODS}

Chemical and reagents

Doxorubicin $\mathrm{HCl}$ (Zhe Jiang Hisun Pharmaceutical Co. Ltd. China) doxorubicinol (Toronto Research Chemical, Canada) and hexamethylphosphoramide as internal standard (Sigma-Aldrich, USA). Reagents such as methanol, acetonitrile, acetic acid obtained from Merck Co. Ltd. (Darmstadt, Germany). Ultrapure water from Sartorius Water Filter System. Whole blood was obtained from The Indonesia Red Cross (Jakarta, Indonesia). Perkin Elmer 226 paper from Perkin Elmer (Waltham, USA).

Preparation of stock solutions, calibration samples, and quality control samples

Doxorubicin $\mathrm{HCl}$, doxorubicinol, and hexamethylphosphoramide (HMPA) as internal standard were prepared by diluting them in methanol to obtain the concentration of $1 \mathrm{mg} / \mathrm{ml}$ for doxorubicin $\mathrm{HCl}, \mathrm{HMPA}$ and $0.5 \mathrm{mg} / \mathrm{ml}$ for doxorubicinol. Doxorubicin $\mathrm{HCl}$ and doxorubicinol stock solutions were used to prepare a working solution containing $0.01 \mathrm{~g} / \mathrm{ml}$ doxorubicin $\mathrm{HCl}$ and doxorubicinol in methanol. Calibration samples were prepared by diluting working solution using whole blood to obtain calibration range of 10-200 $\mathrm{ng} / \mathrm{ml}$ for doxorubicin $\mathrm{HCl}$ and $4-100 \mathrm{ng} / \mathrm{ml}$ for doxorubicinol, at seven-level concentrations each. Quality control solutions were prepared at $30 \mathrm{ng} / \mathrm{ml}$ (QCL), $100 \mathrm{ng} / \mathrm{ml}$ (QCM), and $150 \mathrm{ng} / \mathrm{ml}$ (QCH) for doxorubicin and at $12 \mathrm{ng} / \mathrm{ml}$ (QCL), $50 \mathrm{ng} / \mathrm{ml}(\mathrm{QCM})$, and $75 \mathrm{ng} / \mathrm{ml}(\mathrm{QCH})$ for doxorubicinol by diluting working solution in whole blood.

\section{Sample preparation}

Calibration and quality control samples were prepared by pipetting $30 \mu \mathrm{l}$ aliquots from appropriately spiked whole blood onto the Perkin Elmer 226 paper. This was allowed to dry at room 
temperature for $3 \mathrm{~h}$. DBS discs were made by cutting the blood spot from the Perkin Elmer 226 paper and putting it into a microtube. Twenty-five $\mu \mathrm{l}$ of $0.1 \mu \mathrm{g} / \mathrm{ml}$ HMPA was added to the microtube and mixed well. Then was extracted using $300 \mu$ l distilled water, then was vortexed for 10 seconds and was sonicated for $30 \mathrm{~min}$. After that, $300 \mu \mathrm{l}$ methanol was added into the microtube and was vortexed for 10 seconds and was sonicated for $10 \mathrm{~min}$. It was then centrifuged for about $10 \mathrm{~min}$ at $11200 \mathrm{G}$-force. Five hundred $\mu \mathrm{l}$ supernatant was transferred to a flask and was evaporated at $55{ }^{\circ} \mathrm{C}$ for $20 \mathrm{~min}$ under the gentle stream of nitrogen. The dried extract was reconstituted with $100 \mu \mathrm{l}$ of mobile phase and $10 \mu \mathrm{l}$ aliquot was injected into LC-MS/MS system.

\section{LC-MS/MS conditions}

The experiment was performed on an ACQUITY' ${ }^{\mathrm{m}}$ UPLC system (Waters Corp., Milford, MA, USA) and a Xevo TQD triple quadrupole mass spectrometer (Waters Corp., Manchester, UK) equipped with positive electrospray ionization (ESI+). All data were acquired in centroid mode by the MasslynxTM NT4.1 software and analyzed by QuanLynxTM programme (Waters Corp., Milford, MA, USA). The analyte was separated on Acquity ${ }^{\circledR}$ UPLC BEH C18 column $(1.7 \mu \mathrm{m}$, $2.1 \mathrm{~mm} \times 50 \mathrm{~mm}$, Waters, Milford, MA, USA); column temperature $40 \mathrm{oC}$; and the injection volume was $10 \mu \mathrm{l}$.

The mobile phase consisted of $0.1 \%$ acetic acid (eluent $\mathrm{A}$ ) and acetonitrile (eluent B) at $0.15 \mathrm{ml} / \mathrm{min}$. A gradient program was performed for the elution. Initial composition of eluent was $10 \% \mathrm{~A}$, which was maintained for $5 \mathrm{~min}$, followed by reducing its composition to $5 \% \mathrm{~A}$ at the next two min. Total analytical time was 7 min. The MS condition was using electrospray ionization positive for doxorubicin, doxorubicinol, and hexamethylphosphoramide (HMPA) with $\mathrm{m} / \mathrm{z}$ values: 544.22>397.06; 546.22>363.05; 180.03>135.16, respectively. The capillary voltage used was $3.0 \mathrm{kV}$. Nitrogen temperature and flow rate were controlled at $450{ }^{\circ} \mathrm{C}$ and $500 \mathrm{l} / \mathrm{h}$. Argon was used as the collision gas. The cone and collision voltage doxorubicin, doxorubicinol, and hexamethylphosphoramide were $46 \mathrm{~V}, 42 \mathrm{~V}, 28 \mathrm{~V}$ and $10 \mathrm{~V}, 26 \mathrm{~V}, 14 \mathrm{~V}$, respectively.

\section{Method validation}

Method was validated according to FDA 2018 and EMEA 2011 as the guideline of bioanalysis $[10,11]$.

\section{The lower limit of quantification (LLOQ)}

LLOQ was $10 \mathrm{ng} / \mathrm{ml}$ for doxorubicin and $4 \mathrm{ng} / \mathrm{ml}$ for doxorubicinol, which still fulfill the precision and accuracy requirement. It was tested using 5 replicates. It claimed to fulfill the requirement if the $\%$ diff and \%CV value are within $20 \%$.

\section{Calibration curve}

The working solution containing doxorubicin and doxorubicinol which diluted by whole blood to get seven concentration levels: 10 , $15,30,50,100,150$, and $200 \mathrm{ng} / \mathrm{ml}$ for doxorubicin 4, 6, 12, 25, 50, $75,100 \mathrm{ng} / \mathrm{ml}$ for doxorubicinol. Calibration samples were spotted to the Perkin Elmer 226 paper according to the procedure explained above. Calibration curve measure based on the ratio of doxorubicin and doxorubicinol area to hexamethylphosphoramide area. The correlation coefficient (r) was 0.9878 for doxorubicin and 0.9929 for doxorubicinol.

\section{Selectivity}

The representative chromatograms resulting from the UPLC-MS/MS analysis of blank DBS and spiked LLOQ of doxorubicin, doxorubicinol, and hexamethylphosphoramide are given in fig. 1a and $b$. There were no significantly interfering peaks due to the endogenous components or reagents that were observed for doxorubicin, doxorubicinol, and hexamethylphosphoramide.

\section{Precision and accuracy}

Quality control samples were prepared at four concentration levels for each analyte, which were: $10 \mathrm{ng} / \mathrm{ml}$ (LLOQ), $30 \mathrm{ng} / \mathrm{ml}$ (QCL), 100 $\mathrm{ng} / \mathrm{ml}(\mathrm{QCM}), 150 \mathrm{ng} / \mathrm{ml}(\mathrm{QCH})$ for doxorubicin and $4 \mathrm{ng} / \mathrm{ml}$ (LLOQ), $12 \mathrm{ng} / \mathrm{ml}$ (QCL), $50 \mathrm{ng} / \mathrm{ml}$ (QCM), $75 \mathrm{ng} / \mathrm{ml}$ (QCH) for doxorubicin by diluting the working solutions in whole blood. Each concentration was tested using 5 replicates by within-run and between-run. It fulfills the requirement if \%diff and \%CV obtained within $20 \%$ for LLOQ and within $15 \%$ for other concentrations besides LLOQ.

\section{Recovery}

The mean extraction recoveries of doxorubicin were $81.59 \%$, $80.49 \%$, and $82.43 \%(\mathrm{n}=3)$ at the concentration of QCL, QCM, and $\mathrm{QCH}$, with \%CV values of $1.68 \%, 9.30 \%$, and $8.06 \%$, respectively. The mean extraction recoveries of doxorubicinol were $81.92 \%$, $81.30 \%$, and $86.71 \%(\mathrm{n}=3)$ at the concentration of QCL, QCM, and $\mathrm{QCH}$, with \% CV values of $5.55 \%, 1.58 \%$, and $0.78 \%$, respectively. While for hexamethylphosphoramide was $89.82 \%$ with $\% \mathrm{CV}$ value was $3.35 \%$.

\section{Carryover}

The measured peak area of the blank sample injected after ULOQ calibration standard was between $2.20-13.41 \%$ of the peak area of the analyte at LLOQ for doxorubicin, between $0.94-10.37 \%$ of the peak area of the analyte at LLOQ for doxorubicinol and between $0.18-0.36 \%$ of the peak area of the analyte at LLOQ for hexamethylphosphoramide.

\section{Dilution integrity}

The dilution integrity testing results were acceptable because the dilution still fulfills accuracy and precision requirements with \%diff and $\% \mathrm{CV}$ not more than $15 \%$, which was diluted in human blank whole blood until the concentration of QCH and a half of QCH.

\section{Matrix effects}

The internal standard normalized matrix factor value of doxorubicin were 0.93 and 0.91 at the concentration of QCL and QCH, with \%CV of $5.07 \%$ and $7.69 \%$, respectively. The internal standard normalized matrix factor value of doxorubicinol was 0.91 and 0.96 at the concentration of QCL and QCH, with \%CV of $7.02 \%$ and $6.70 \%$, respectively. While for the hexamethylphosphoramide, the mean matrix effect was $93.24 \%$ with \%CV of $5.28 \%$. These data indicate that the ME (ion suppression or enhancement) from human plasma was negligible under the current conditions.

\section{Stability}

Storage of stock solutions of doxorubicin, doxorubicinol and hexamethylphosphoramide in methanol at room temperature for 24 $\mathrm{h}$ and in the refrigerator $\left(-4^{\circ} \mathrm{C}\right)$ for $1 \mathrm{mo}$ (long term stability) did not alter the analyte of doxorubicin, doxorubicinol, and hexamethylphosphoramide. The stability test results of doxorubicin and doxorubicinol in DBS is stable enough during sample preparation, storage conditions and autosampler.

\section{Application of the method}

After approval (032/KEPK/III/2019) by the Ethics Committee of Dharmais Cancer Hospital, a total of 25 breast cancer patients who were taking chemotherapy treatment with doxorubicin on any stage of breast cancer enrolled in the study. They signed the informed consent prior participating in this study. The study inclusion criteria were patient that has been diagnosed with breast cancer who receive doxorubicin in their therapy regimen, while the exclusion criteria were the patient who has not got doxorubicin therapy on their regiment therapy or declared they were unwilling to participate in the study by not signing the informed consent sheet. Finger prick blood samples were collected from 25 breast cancer patients of Dharmais Cancer Hospital, Jakarta, Indonesia. Blood samples are taken $40 \mathrm{~min}$ after doxorubicin administration. Around $100 \mu \mathrm{L}$ blood samples were collected from the fingertips. Blood was taken by finger prick technique using a lancet and the first drop of blood from fingertip was thrown away by rubbing it with an alcohol swab; then, the blood drops were collected in a $0.5 \mathrm{ml} \mathrm{K} \mathrm{K}_{3}$ EDTA microtube. After that, $30 \mu \mathrm{L}$ aliquot blood was immediately transferred to DBS paper using a calibrated pipette. Next, the DBS paper was dried at room temperature for $3 \mathrm{~h}$. After it was dried, DBS paper was stored in a seal bag where the silica gel was inserted into it. 


\section{RESULTS AND DISCUSSION}

\section{Chromatography and sample preparation}

There are several previous studies about doxorubicin and doxorubicinol analysis, such as by Sottani, Poggi, Melchiorre, et al. in 2013 and study by DiFrancesco, Griggs, Donnelly, et al. in 2007. The two studies used UHPLC-MS/MS and human plasma as sample; extracted by solid phase extraction [6,7]. However, analysis of drugs with plasma sample has several disadvantages such as invasive sampling and needed more volume of sample [8]. For this reason, in this study, DBS sample is choosen because it is less invasive and it needed less volume of sample [9].

Sensitive and selective methods were needed for DBS technique because it has low concentration and it use whole blood, which still contains many interferences; hence, LC-MS/MS is suitable to analyze it. This study was performed using Acquity ${ }^{\circledR}$ UPLC C-18 BEH $(2.1 \mathrm{x}$ $100 \mathrm{~mm}), 1.7 \mu \mathrm{m}$ to separate compound of interest with total analytical time $7 \mathrm{~min}$. Sample preparation was done by spotted $30 \mu \mathrm{L}$ aliquot blood on Perkin Elmer 226 paper. Extraction process was performed as it stated earlier. Retention time of doxorubicin, doxorubicinol and HMPA are 2.93; 2.93; and 3.03, respectively (fig. 1)

\section{Method validation}

Calibration curve obtained was linear in the range within $10-200 \mathrm{ng} / \mathrm{ml}$ for doxorubicin and 4-100 $\mathrm{ng} / \mathrm{ml}$ for doxorubicinol with correlation coefficient ( $r$ ) value $\geq 0.9932$ and $\geq 0.9988$, respectively. Precision and accuracy's result were shown in table 1 . The data demonstrate that the accuracy and precision values are within the acceptable criteria based on FDA 2018 [10] and EMA 2011 guideline [11].
Doxorubicinol

(a)

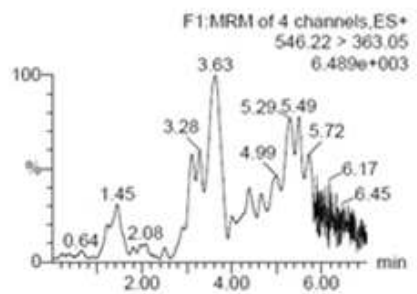

Doxorubicinol

F1.MRM of 4 channets. ES.

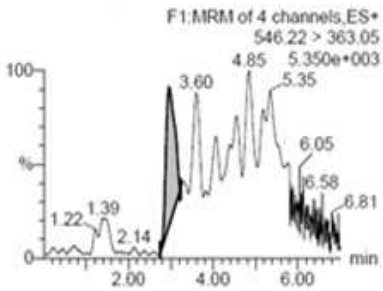

Doxorubicinol

F1.MRM of 4 channeis, ES

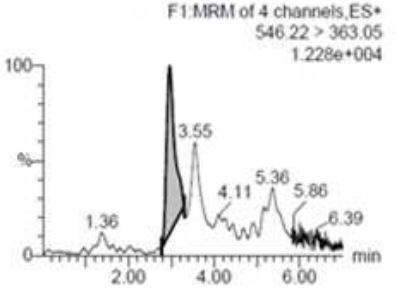

Doxorubicinol

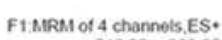

$$
\begin{array}{r}
546.22>363.05 \\
2910 \mathrm{e}+004
\end{array}
$$

(d)

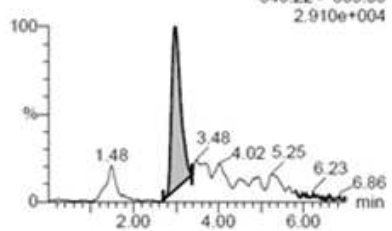

Doxorubicinol

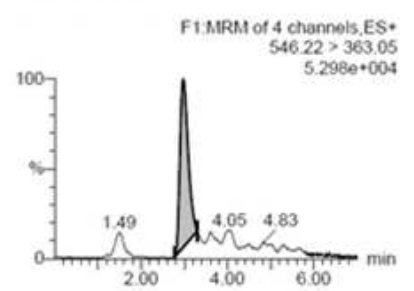

Doxorubicin

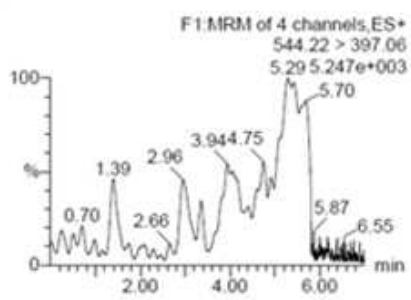

Doxorubicin
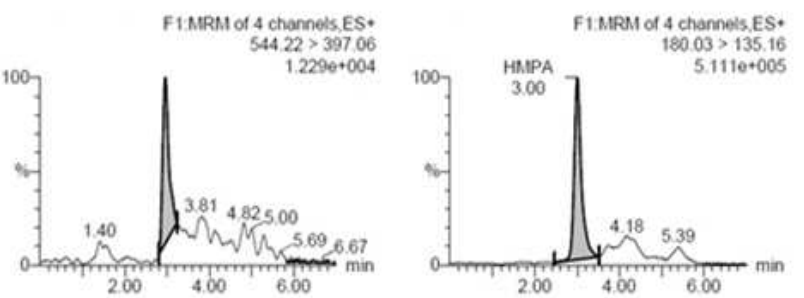

Doxorubicin

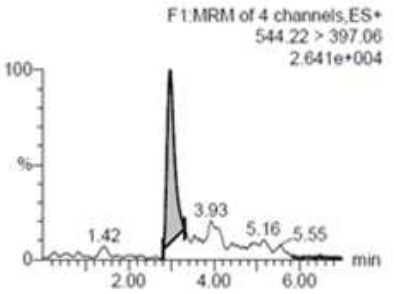

HMPA

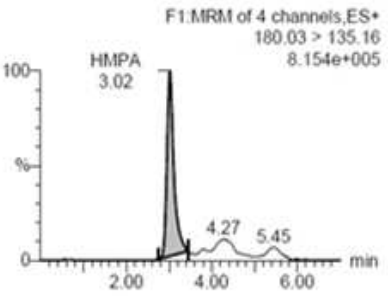

Doxorubicin

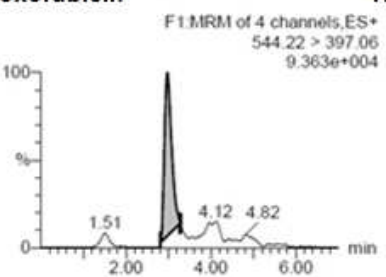

HMPA

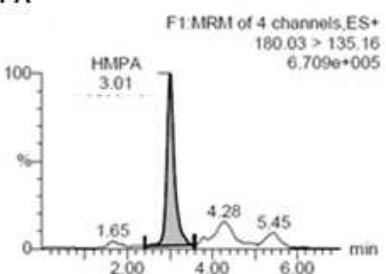

Doxorubicin

HMPA
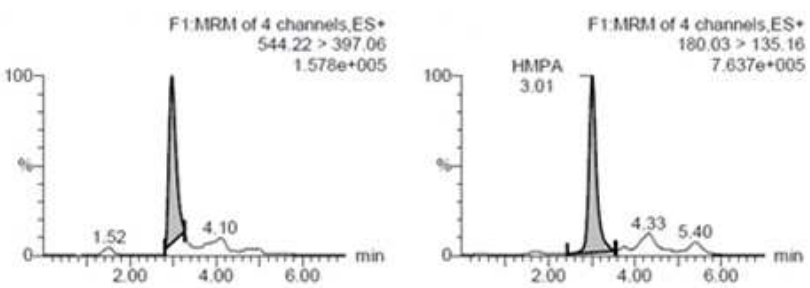

Fig. 1: Chromatogram of blank (a), LLOQ (b), QCL (c), QCM (d) and QCH (e) 
Table 1: The intra-day accuracy and precision of doxorubicin (up) and doxorubicinol (down)

\begin{tabular}{lll}
\hline Nominal conc. $(\mathbf{n g} / \mathbf{m l})$ & Mean accuracy (\%diff) & Precision (\%CV) \\
\hline 10.00 & -12.16 to 0.87 & 5.60 \\
30.00 & -11.04 to 11.59 & 11.87 \\
100.00 & -7.84 to 11.00 & 8.82 \\
150.00 & -10.65 to 11.45 & 9.77 \\
Nominal conc. $(\mathbf{n g} / \mathbf{m l})$ & Mean accuracy (\%diff) & Precision (\%CV) \\
10.00 & -8.17 to 15.18 & 9.22 \\
30.00 & -5.14 to 7.95 & 5.31 \\
100.00 & -13.15 to 11.76 & 11.01 \\
150.00 & 8,31 to 13,38 & 1.91 \\
\hline
\end{tabular}

\section{Clinical application}

The results of the analysis on 25 samples showed that all samples contained doxorubicin and doxorubicinol with a certain concentration as in fig. 4 . The highest doxorubicin content was found in SN 17 patients of $93.75 \mathrm{ng} / \mathrm{ml}$ and the lowest level of $11.01 \mathrm{ng} / \mathrm{ml}$ was present in SN 10 (fig. 2). Based on the data obtained, it can be concluded that doxorubicin levels in the DBS between patients vary widely. This variation between patients was also found in the results of doxorubicinol analysis. The highest doxorubicinol levels were present in SN 24 of $58.57 \mathrm{ng} / \mathrm{ml}$ and the lowest levels of $5.80 \mathrm{ng} / \mathrm{ml}$ were present in patients with SN 14 (fig. 3). The results of the analyzes obtained may have varied level of concentration because based on the previous study stated that CBR1 gene polymorphism correlated with high concentrations of doxorubicin and the possibility of intracellular conversion to lower doxorubicinol in the patient's body [3]. Most of the patients have doxorubicin concentration level higher than doxorubicinol. Whereas, in 3 patients, the concentration levels of doxorubicinol were found to be much higher compared to the concentration levels of doxorubicin in SN 8, SN 10 and SN 24 patients. Other previous study by Covarrubias et al., (2009) stated that the higher concentration of doxorubicinol has a relationship with untranslated CBR1 polymorphism [12].

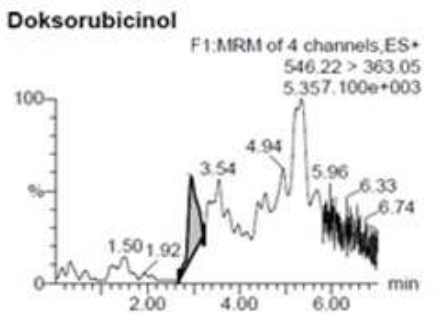

Doxorubicinol

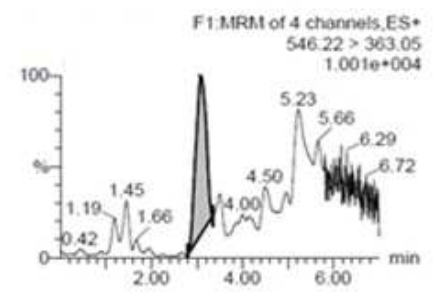

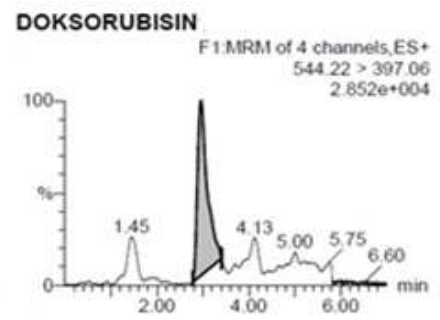

Doxorubicin

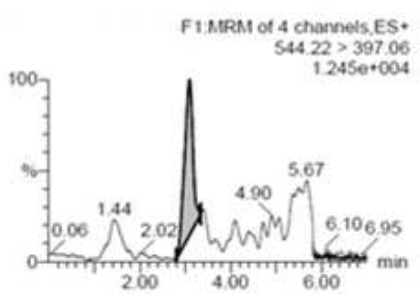

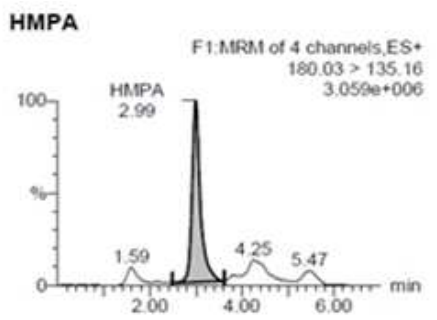

HMPA

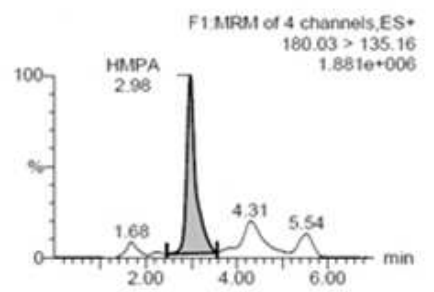

Fig. 2: Chromatogram of highest (up) and lowest (down) doxorubicin levels

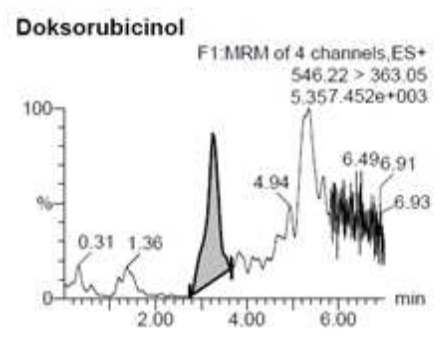

Doxorubicinol

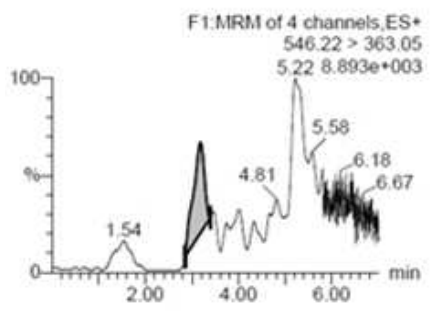

DOKSORUBISIN

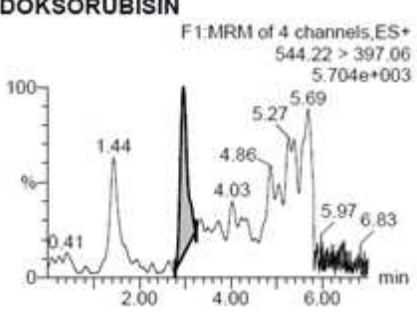

Doxorubicin

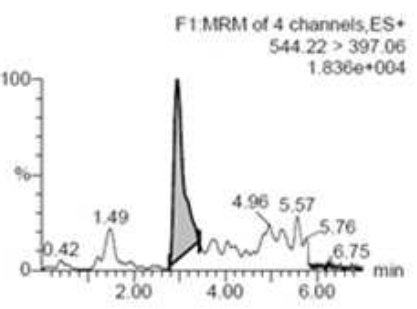

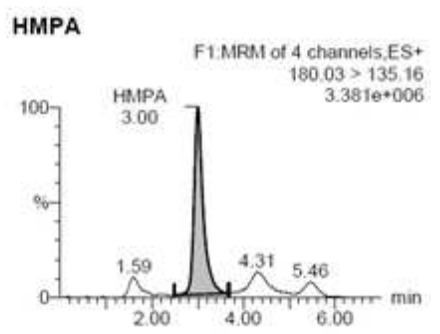

HMPA

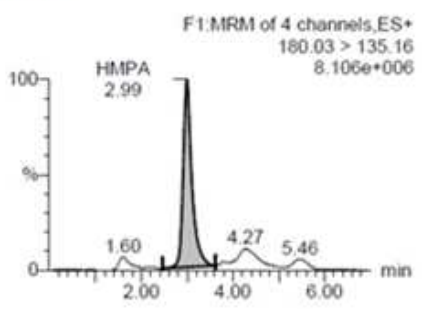

Fig. 3: Chromatogram of highest (up) and lowest (down) doxorubicinol levels 


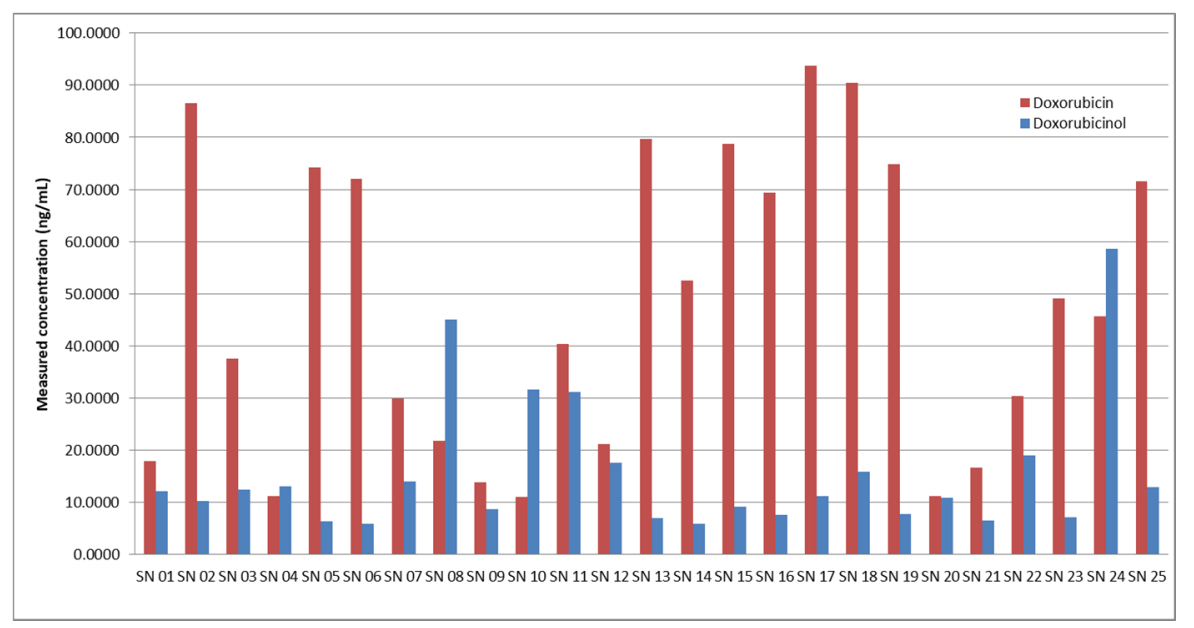

Fig. 4: Graphic of inter-patient doxorubicin and doxorubicinol levels in DBS samples

Based on study, it was stated that the incidence of cardiomyopathy increased at a rate of $4 \%$ at doses of $500-550 \mathrm{mg} / \mathrm{m}^{2}, 18 \%$ at doses of $551-600 \mathrm{mg} / \mathrm{m}^{2}$ and $36 \%$ at doses $>600 \mathrm{mg} / \mathrm{m}^{2}$ (all cumulative doses) [2]. In this study, the obtained cumulative doses of all patients were in the range of $49.11 \mathrm{mg} / \mathrm{m}^{2}$ to $303.70 \mathrm{mg} / \mathrm{m}^{2}$ based on doses that accepted by the patient according to the body surface area. It can be concluded that all of the patients have cardiomyopathy incidence rates of $<4 \%$. Based on the patient's medical record, there were no records of heart problems in the patient, which means that chemotherapy in Dharmais Cancer Hospital has been done well.

\section{CONCLUSION}

The method successfully applied to 25 breast cancer patients, which resulted in doxorubicin concentration ranged from $11.01 \mathrm{ng} / \mathrm{ml}$ to $93.75 \mathrm{ng} / \mathrm{ml}$ and doxorubicinol concentration ranged from 5.80 $\mathrm{ng} / \mathrm{ml}$ to $58.57 \mathrm{ng} / \mathrm{ml}$. Cumulative doses of all patients were in the range of $49.11 \mathrm{mg} / \mathrm{m}^{2}$ to $303.70 \mathrm{mg} / \mathrm{m}^{2}$, which have cardiomyopathy incidence rates $<4 \%$. This study offers efficiency for therapeutical drug monitoring doxorubicin therapy that has the potential to increase the survival rate of the breast cancer patient.

\section{ACKNOWLEDGMENT}

This study was supported by Directorate of Research and Community Service (DRPM) Universitas Indonesia for the financial support this research with Grant Number: NKB-0203/ UN2.R3.1/HKP.05.00/2019 and Dharmais Cancer Hospital, Jakarta, Indonesia.

\section{FUNDING}

Directorate of Research and Community Service (DRPM) Universitas Indonesia.

\section{AUTHORS CONTRIBUTIONS}

Prof. Dr. Yahdiana Harahap-Design, the study, and be responsible for the whole study and create the report, Sabrina Nur Amalia-Perform the blood sampling and analyze the dried blood spot samples, Aldhi Anarta-Perform the optimization and development of the bioanalytical method, Ramadhan-Supervise the clinical part of the research.

\section{CONFLICT OF INTERESTS}

\section{Declared none}

\section{REFERENCES}

1. Wells B, Dipiro J, Schwinghammer $\mathrm{T}$, Dipiro C Pharmacotherapy Handbook. Pharmacotherapy Handbook; 2009. https://doi.org/10.1345/aph.10237.

2. Luu AZ, Chowdhury B, Al-Omran M, Teoh H, Hess DA, Verma S. Role of the endothelium in doxorubicin-induced cardiomyopathy. JACC Basic Transl Sci 2018;3:861-70.
3. Lal S, Sandanaraj E, Wong ZW, Ang PCS, Wong NS, Lee EJD, et al. CBR1 and CBR3 pharmacogenetics and their influence on doxorubicin disposition in Asian breast cancer patients. Cancer Sci 2008;99:2045-54.

4. Schaupp CM, White CC, Merrill GF, Kavanagh TJ. Chemico-biological interactions metabolism of doxorubicin to the cardiotoxic metabolite doxorubicinol is increased in a mouse model of chronic glutathione deficiency: a potential role for carbonyl reductase 3 . Chem Biol Interactions 2015;234:154-61.

5. Evans G. A handbook of bioanalysis and drug metabolism. Taylor and Francis; 2004. Available from: https://books.google.co.id/books?id=vKgikgEACAAJ [Last accessed on 15 Nov 2019]

6. Sottani C, Poggi G, Melchiorre F, Montagna B, Minoia C. Simultaneous measurement of doxorubicin and reduced metabolite doxorubicinol by UHPLC-MS/MS in human plasma of HCC patients treated with TACE. J Chromatogr B: Anal Technol Biomed Life Sci 2013;916:71-8.

7. DiFrancesco R, Griggs JJ, Donnelly J, DiCenzo R. Simultaneous analysis of cyclophosphamide, doxorubicin and doxorubicinol by liquid chromatography coupled to tandem mass spectrometry. J Chromatogr B: Anal Technol Biomed Life Sci 2007;852:545-53.

8. Zakaria R, Allen KJ, Koplin JJ, Roche P, Greaves RF. Advantages and challenges of dried blood spot analysis by mass spectrometry across the total testing process. EJIFCC 2016;27:288-317.

9. Pedersen L, Andersen Ranberg K, Hollergaard M, Nybo M. Quantification of multiple elements in dried blood spot samples. Clin Biochem 2017;50:703-9.

10. Food and Drug Administration. Bioanalytical Method Validation Guidance for Industry. US; 2018.

11. European Medicines Agency. Guideline on bioanalytical method validation. EMEA/CHMP/EWP/192217/2009 Rev Corr 2011;44:1-23.

12. Gonzalez Covarrubias V, Zhang J, Kalabus JL, Relling MV, Blanco JG. Pharmacogenetics of human carbonyl reductase 1 (CBR1) in livers from black and white donors. Drug Metab Dispos 2009;37:400-7.

13. Brunton L, Chabner BA, Knollman B. Goodman and gilman's the pharmacological basis of therapeuticsmcgraw-hill education; 2011. Available from: https://books.google.co.id/ books?id=e_yAOpyyaowC [Last accessed on 15 Nov 2019].

14. Sherwood L. Fundamentals of Human Physiology. Cengage Learning; 2011. Available from: https://books.google. co.id/books?id=qXwIAAAAQBAJ [Last accessed on 15 Nov 2019].

15. Harmita K, Harahap Y, Supandi. Liquid chromatographytandem mass spectrometry (LC-MS/MS). Jakarta: ISFI Penerbitan; 2019. 